\title{
First report of Eurytoma plotnikovi Nik. (Hymenoptera, Eurytomidae), a seed parasite of pistachio, in Sicily (Italy)
}

\begin{abstract}
The pistachio seed wasp, Eurytoma plotnikovi Nik.(Hymenoptera, Eurytomidae), is a new pest recently arrived in pistachio orchards in central-western Sicily (Italy). Information on the damaging effects of this seed wasp in the affected areas is provided.
\end{abstract}

Riassunto - Prima segnalazione di Eurytoma plotnikovi Nik. (Hymenoptera, Eurytomidae), dannoso per il seme di pistacchio in Sicilia (Italia)

La presenza di Eurytoma plotnikovi Nik. (Hymenoptera, Eurytomidae) in alcuni pistacchieti della Sicilia centro-occidentale viene segnalata per la prima volta. Vengono inoltre fornite informazioni sul danno prodotto dall'imenottero, nelle aree infestate.

Key words: pistachio seed wasp, new record, Megastigmus pistaciae.

Edible pistachio (Pistacia vera L.) nuts infested with larvae of an unidentified wasp were collected during an insect survey conducted in spring 2011 in pistachio orchards in central-western Sicily (latitude 37 $51^{\prime}$ '01" N; longitude 1352'64” E). The wasp larvae, reared under laboratory conditions, developed into adults that were identified as Eurytoma plotnikovi, an indigenous pest of inedible nuts of the ornamental pistachio ( $P$. chinensis) in China (Qin et al., 2007; Tian et al., 1994). The occurrence of this pistachio seed wasp in Sicily is a new record for Italy. In the surveyed orchards, E. plotnikovi was associated with another wasp, the pistachio seed chalcid, Megastigmus pistaciae Walker that is native to the Mediterranean region. In addition to China, the pistachio seed wasp is present in Tunisia (Jarraya \& Helali, 1978), Iran (Basirat \& Seyedoleslami, 2000), Israel (Izhaki, 1998), Turchia (Doğanlar et al., 2009), Greece (Mourikis, et al., 1998) and in other pistachio producing countries in the Middle East. A total of 553 nuts were collected in the infested Sicilian pistachio orchards and dissected for wasp infestation. All the nuts presenting the wasp larvae (254) were isolated under laboratory conditions waiting for the eclosion of the adults. An association of 177 and 77 specimens of $E$. plotnikovi and M. pistaciae Walker, respectively was produced. The damage induced by E. plotnikovi in the surveyed orchards has been noticed since 2009 by the growers 


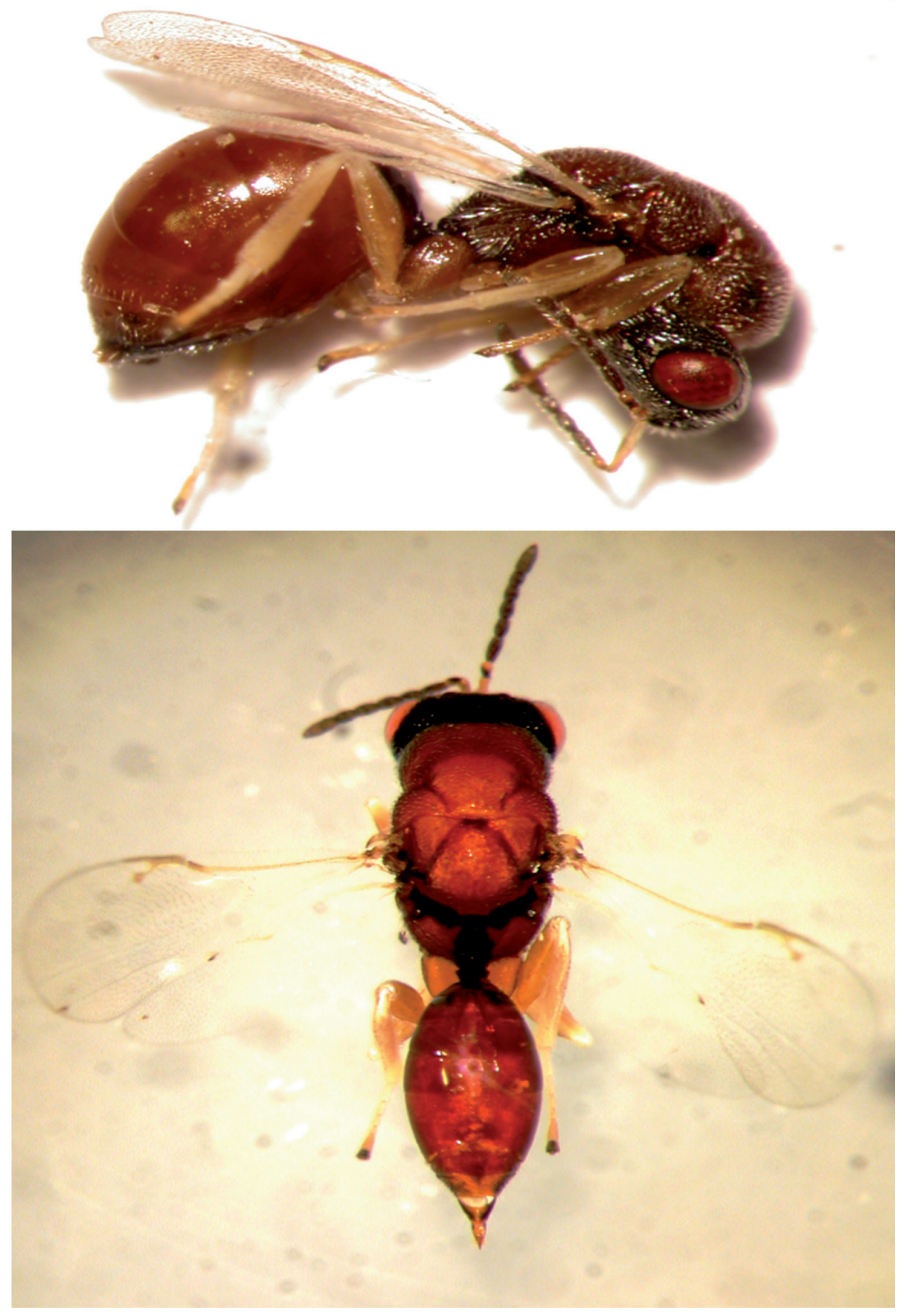

Eurytoma plotnikovi Nik.: lateral (top) and dorsal view (bottom) of adult. 
who confused it with that caused by M. pistaciae. According to the literature, this new pistachio seed wasp completes one generation per year. The insect overwinters as a full grown larva inside the infested pistachio nuts which remain on the tree or fall to the ground. Adult emerges from the seeds in late April early May. The newly emerged females search for unripe pistachio nuts left on the trees or on the ground to deposit their eggs. The hatched larvae feed on the nuts until all or almost all the seed embryo is consumed and then enter diapause usually by July (Braham, 2005). According to Basirat and Seyedoleslami, (2000) each pistachio nut allows the development of only one wasp specimen. However, studies conducted in Iran and Tunisia, where the two pistachio wasps are present, indicate that E. plotnikovi is able to outperform M.pistaciae displacing it and becoming the dominant species infesting pistachio orchards (Basirat and Seyedoleslami, 2000; Braham, 2005). The early emergence (about one month earlier) of E. plotnikovi adults, compared to $M$. pistaciae, favors its spread and rapid colonization of pistachio nuts (Jerraya and Bernard, 1971; Braham, 2005). Poor management practices of the wasp infestations may also influence the spread of E. plotnikovi in pistachio orchards (Wu et al., 2009). The results of chemical control trials reported in the literature indicate that stem injections of neonicotinoids are the most effective measures for managing infestations of E. plotnikovi, providing better results than spray and drench applications of this product. Taking into consideration the importance of the pistachio industry as an economic resource in eastern Sicily, the only Italian region where pistachios are grown, biological and ecological studies of E. plotnikovi in the environmental conditions of Sicily are needed to prevent the spread of this pest from west into east Sicily (Bronte Municipality) and, in general, all over the country.

\section{ACKNOWLEDGEMENTS}

Sincere thanks are expressed to prof. G. Viggiani and prof. S. Laudonia, Naples University, for confirming the identification of the insect.

\section{REFERENCES}

Basirat M., Seyedoleslami H., 2000 - Biology of Pistachio seed wasp Eurytoma plotnikovi Nikoloskaya (Hym.: Eurytomidae) in Isfahan Province, Iran. In: J. Sci. \& Tech. Agric. \& Nat. Resour., Vol 4, No. 1, p. 148 (Abstract).

BRAHAM M., 2005 - Management of the pistachio seed wasp Eurytoma plotnikovi Nikolskaya (Hymenoptera, Eurytomidae) in Tunisia: Integration of pesticides sprays and other means of control. In: International Pest Control, Vol. 47(6), p. 319-324.

DoĞANLAR M., KARADAĞ S., Mendel, Z., 2009 - Notes on pistachio seed wasps from two locations in the east Mediterranean. Phytoparasitica, 37:147-151.

IZHAKI I., 1998 - The relationships between fruit ripeness, wasp seed predation, and avian fruit removal in Pistacia palaestina. Israel Journal of Plant Sciences 46(4): 273-278.

Jarraya A.; Helali T., 1978 - Contribution to the study of the insect fauna of pistachio. On the spatial distribution of Megastigmus pistaciae Walk. (Hym. Torymidae) and of Eurytoma plotnikovi Nik. (Hym. Eurytomidae) in Tunisia. Bulletin des Recherches Agronomiques de Gembloux 13(3): 215-252. 
JERRAYA A., BERNARD J., 1971 - Premières observations bioécologiques sur Megastigmus pistaciae en Tunisie. In: Annales de l'Institut National de la Recherche Agronomique de Tunisie, Vol. 44(3), p. 1-26.

Mourikis P. A., Tsourgianni A., ChitZanidis A., 1998 - Pistachio nut insect pests and means of control in Greece. Acta Horticulturae, 470: 604-611.

QIN F., Guo T., Song M., Liu Z., 2007 - Study on Eurytoma plotnikovi Nikolskaya. Journal of Jiangsu Forestry Science \& Technology. DOI: CNKI:SUN:JSLY.0.2007-06-014.

TIAN S.B., QIN X.R., ZHAO X., 1994 - Infestation charactersitics of the larvae of Eurytoma plotnikovi and their control.Plant Protection, China 20(2):15-16.

Wu Y., Wen X., ChEN X., Li W., ZhANG Y., LiU M., 2009 - Eurytoma plotnikovi: incidence harms and the management countermeasure. Forest By-Product and Speciality in China. DOI: CNKI:SUN:CTFL.0.2009-03-04.

SANTI LONGO, Pompeo Suma - Dipartimento di Gestione dei Sistemi Agroalimentari e Ambientali, Sezione Entomologia Agraria, Università degli Studi di Catania, 100 Via Santa Sofia, 95123 Catania, Italy.E-mail: longosan@unict.it

Accepted 12 December 2011 